\author{
반복모형을 이용한 한우 초음파 측정형질의 유전모수추정 \\ 박철현 ${ }^{1} \cdot$ 구양모 $^{2} \cdot$ 김병우 ${ }^{3} \cdot$ 선두원 $^{1} \cdot$ 김정일 $^{2} \cdot$ 송치은 $^{2} \cdot$ 이기환 $^{2} \cdot$ 이재윤 $^{2} \cdot$ 정용호 ${ }^{2} \cdot$ 이정규 $^{1 *}$ \\ ${ }^{1}$ 경상대학교 응용생명과학부(BK21)· 농업생명과학연구원, ${ }^{2}$ 한국종축개량협회, ${ }^{3}$ 부산대학교
}

\title{
Repeated Records Animal Model to Estimate Genetic Parameters of Ultrasound Measurement Traits in Hanwoo Cows
}

\author{
Cheol-Hyeon Park ${ }^{1}$, Yang-Mo Koo ${ }^{2}$, Byung-Woo Kim ${ }^{3}$, Du-Won Sun ${ }^{1}$, Jung-Il Kim ${ }^{2}$, Chi-Eun Song ${ }^{2}$, Ki-Hwan Lee ${ }^{2}$, \\ Jae-Youn Lee ${ }^{2}$, Yeoung-Ho Jeoung ${ }^{2}$, Jung-Gyu Lee ${ }^{1 *}$ \\ ${ }^{1}$ GyongSang Nat'1 Univ (Insti. of Agric. \& Life Sci.), JinJu 660-701, Korea, ${ }^{2}$ Korean Animal Improvement Association, \\ Seocho, Seoul 137-871, Korea, ${ }^{3}$ Pusan National Univ (Department of Animal Science), Pusan 609-735, Korea
}

\begin{abstract}
The present study data were obtained from 36,894 cows in Korea Animal Improvement Association from 2001 to 2009 which was subjected for ultrasound measurements (eye muscle area, back-fat thickness, marbling score) and descent. Repeated record models were carried out using 7,913 of 36,894 of total animal traits. The ultrasound measured traits and performance test data were used to study the chest girth, body condition score, eye muscle area, back-fat thickness and marbling score with genetic correlation and parameters for the ultrasound measured traits using REMLF90 program. Genetic correlation of eye muscle area with back-fat thickness, marbling score and back-fat thickness with marbling score were noticed in repeated records animal model as $0.69,0.54$, and 0.59 , whereas in multiple trait animal model method were $0.07,0.66$, and 0.39 , respectively. Repeated records of animal models were used as positive correlation of traits. Multiple trait animal models were used as negative correlation of eye muscle area with marbling score. The analysis on repeat records of animal models using ultrasound measurements about Korean cattle showed positive effects for each traits. In comparison differences between the repeat records of animal models and multiple trait animal models was found with higher traits of her, the heritability and repeatability was found higher in repeat records animal models. In light of these assessments, carcass traits by ultrasound measurements are expected to help and improve an accurate analysis of each trait and if the research analysis using repeat records of animal models continue when we estimate genetic ability of these traits.
\end{abstract}

(Key words : Carcass trait, Repeated records animal model, Ultrasound)

$$
\text { 서 론 }
$$

1970년대부터 한우개량사업이 실시되면서, 지속적으로 한우의 체형개량이 주로 이루어져왔다. 하지만 1990년대에 접어들면서 소 비자들의 한우고기 구매성향의 변화에 따라 양적인 면에서 질적인 면으로 개량방향이 바뀌었으며, 1998년 외환위기와 쇠고기 시장의 개방화로 한우 산업이 위기에 봉착하게 되었다. 하지만 당대검정과 후대검정을 통하여 지속적으로 우수한 개체를 선발한 결과 한우의 체중이 증가하였다. 하지만 후대 검정사업을 통한 개체선발은 시간 과 비용이 많이 소요된다는 단점 (Roh. 2010)으로 90년대 말에 접 어들면서 초음파 측정기술이 도입되었다.

초음파 측정기술은 생체상태에서 도체형질 즉 배최장근단면적, 등지방두께 및 근내지방도를 알 수 있는 기술로써 외국의 경우 이
미 오래전 산업화에 적용되었다(Brethour. 1992, Waldner. 1992 등). Hamlin 등 (1995)은 생체에서 초음파 측정형질을 이용하여 정육율을 계산하였으며, $\mathrm{Kim}$ 등 (1995)은 한우개량사업소에서 92 년부터 93년까지 비거세우와 거세우에 대하여 초음파 생체단층촬 영을 이용하였다. 초음파 측정기술을 이용하면 도체형질(배최장근 단면적, 등지방두께, 근내지방도)을 추정하는 방법중에서 효율적으 로 비교적 정확히 해석 할 수 있다. 발육상태와 생축으로 부터의 육질을 실시간으로 측정하여 출하시기 조절 및 육질평가를 할 수 있으며 우수한 개체의 조기 선발에 초음파를 활용하여 조기선발을 한다면 기존의 후대검정체계보다 시간을 단축하고 비용을 절감 할 수 있을 것으로 사료된다. 하지만 이러한 장점이 있는 반면에 측정 자, 화상판독자, 개체의 보정 상태, 동기군 설정 등 필드에서 자료 를 수집하거나 조사함에 있어 상당한 오차를 안고 있는 것도 사실

* Corresponding author: Jung-Gyu Lee, Gyeongsang National University, Jinju-si, Gyeonsangnam-do, 660-701, Korea. Tel: +82-55751-5509, E-mail: jglee@gnu.ac.kr 
이다. 이렇게 오차가 많이 발생할 여지가 있는 초음파 측정을 생애 1 회 측정치만을 가지고 개량에 이용하는 것보다는 2 회 이상의 측 정치를 이용하는 것이 오차를 줄일 수 있을 것으로 사료된다.

따라서 본 연구는 한우 암소 초음파 측정자료 특징을 알아보고, 측정형질에 대한 유전모수를 추정하여 육질 또는 육량 개량을 위한 기초자료를 제공하기 위해 수행되었다.

\section{재료 및 방법}

\section{1. 공시재료 및 조사 항목}

본 연구는 2001년부터 2009년까지 한국종축개량협회에 의해 수 집된 한우 암소 초음파 측정형질 (배최장근단면적, 등지방두께 및 근내지방도)이 있는 36,893 두를 이용하였고, 그 중 반복측정이 이 루어진 개체는 7,913두였다. 초음파 측정에 사용된 한우 암소의 출 생년도, 출생계절, 측정년도, 측정계절, 연령, 지역에 대한 두수는 Table 1에 표시한 바와 같다.

\section{2. 유전모수의 추정}

유전모수 추정을 위한 동기군 설정에는 측정연도, 측정지역 및 농가를 적용하였으며, 출생년도, 출생계절을 하나의 효과로 통합하 여 설정했으며, 측정연령에 대해서는 측정일령으로 변환하여 공변 량으로 적용하였다. 측정계절은 동기군 설정에 있어서 큰 차이를 보이지 않아 모형에서 제외하였다.

Table 1. Number of records of Hanwoo by year of birth, season of birth, year of measurement, season of

\begin{tabular}{|c|c|c|c|c|c|c|c|c|c|c|c|}
\hline SOB & No. & SOM & No. & $\mathrm{AM}$ & No. & $\mathrm{LO}$ & No. & YOM & No. & $\mathrm{YOB}$ & No. \\
\hline Spring & 12,495 & Spring & 6,848 & 1 & 897 & $\overline{\mathrm{GG}}$ & 24,333 & 2001 & 1,579 & 1996 & 487 \\
\hline Summer & 9,956 & Summer & 11,724 & 2 & 10,061 & KW & 876 & 2002 & 2,829 & 1997 & 898 \\
\hline Fall & 5,095 & Fall & 12,140 & 3 & 9,863 & $\mathrm{CB}$ & 6,298 & 2003 & 2,372 & 1998 & 1,522 \\
\hline \multirow[t]{10}{*}{ Winter } & 9,347 & Winter & 6,181 & 4 & 6,694 & $\mathrm{CN}$ & 1,483 & 2004 & 2,418 & 1999 & 2,788 \\
\hline & & & & 5 & 3,873 & $\mathrm{JB}$ & 759 & 2005 & 4,091 & 2000 & 3,763 \\
\hline & & & & 6 & 2,506 & $\mathrm{JN}$ & 1,636 & 2006 & 4,403 & 2001 & 3,752 \\
\hline & & & & 7 & 1,457 & GB & 816 & 2007 & 4,822 & 2002 & 3,796 \\
\hline & & & & 8 & 869 & GN & 692 & 2008 & 8,982 & 2003 & 4,345 \\
\hline & & & & 9 & 504 & & & 2009 & 5,397 & 2004 & 4,284 \\
\hline & & & & 10 & 169 & & & & & 2005 & 4,457 \\
\hline & & & & & & & & & & 2006 & 4,340 \\
\hline & & & & & & & & & & 2007 & 2,117 \\
\hline & & & & & & & & & & 2008 & 344 \\
\hline Total & 36,893 & Total & 36,893 & Total & 36,893 & Total & 36,893 & Total & 36,893 & Total & 36,893 \\
\hline
\end{tabular}

YOB : Year of birth, SOB : Season of birth, YOM : Year of measurement, SOM : Season of measurement, AM : Age at measurement (year), LO : Location of measurement, GG : Gyeonggi, GW : Gangwon, CB : Chungbuk, CN : Chungnam, JB : Jeonbuk, JN : Jeonnam, GB : Gyeongbuk, GN : Gyeongnam.
(1) Multiple trait animal model

배최장근단면적, 등지방두께 및 근내지방도에 대한 상가적 유전 효과에 대한 유전모수 및 육종가 추정을 위하여 (1)과 같은 다형질 혼합모형을 이용하였다.

$\mathrm{Y}_{\mathrm{ijkl}}=\mu_{\mathrm{i}}+\mathrm{YAF}_{\mathrm{ij}}+\mathrm{YS}_{\mathrm{ik}}+\mathrm{b}_{\mathrm{i}} \mathrm{X}_{\mathrm{ijkl}}+\mathrm{a}_{\mathrm{ijkl}}+\mathrm{e}_{\mathrm{ijkl}}$

여기서, $\mathrm{Y}_{\mathrm{ijkl}}$ 는 $\mathrm{ijkl}$ 의 각 형질들에 대한 관측치, $\mu_{\mathrm{i}}$ 는 $\mathrm{i}$ 번째 형질 의 전체평균, $\mathrm{YAF}_{\mathrm{ij}}$ 는 $\mathrm{i}$ 번째 형질의 $\mathrm{j}$ 번째 측정년도-측정지역-농 가의 고정효과 $(1,2,3, \cdots, 761), \mathrm{YS}_{\mathrm{ik}}$ 는 $\mathrm{i}$ 번째 형질의 $\mathrm{k}$ 번째 출생년도 -출생계절 $\mathrm{i}=(1,2,3, \cdots, 48), \mathrm{b}_{\mathrm{i}}$ 는 측정일령의 1 차식 회귀계수, $\mathrm{X}_{\mathrm{ijk} 1}$ 는 $\mathrm{i}$ 번째 형질의 1 번째 측정일령의 공변량(Covariate), $\mathrm{a}_{\mathrm{ijk} k}$ 는 개체 의 상가적 유전효과 $\mathrm{N}(0, \mathrm{G}), \mathrm{e}_{\mathrm{ijkl}}$ 는 각 측정치의 임의오차 $\sim \mathrm{N}(0, \mathrm{R})$

\section{(2) Repeated records animal model}

각 형질에 대한 상가적 유전효과 및 영구환경효과에 대한 유전모 수 및 육종가 추정을 위하여 (2)와 같은 반복모형을 이용하였다.

$$
\mathrm{Y}_{\mathrm{ijkl}}=\mu_{\mathrm{i}}+\mathrm{YAF}_{\mathrm{ij}}+\mathrm{YS}_{\mathrm{ik}}+\mathrm{b}_{\mathrm{i}} \mathrm{X}_{\mathrm{ijkl}}+\mathrm{PE}_{\mathrm{ijkl}}+\mathrm{a}_{\mathrm{ijkl}}+\mathrm{e}_{\mathrm{ijkl}} \cdots \cdots \cdots \cdots \cdot(2)
$$

여기서, $\mathrm{Y}_{\mathrm{ijkl}}$ 는 $\mathrm{ijkl}$ 의 각 형질들에 대한 관측치, $\mu_{\mathrm{i}}$ 는 $\mathrm{i}$ 번째 형질 의 전체평균, $\mathrm{YAF}_{\mathrm{ij}}$ 는 $\mathrm{i}$ 번째 형질의 $\mathrm{j}$ 번째 측정년도-측정지역-농 가의 고정효과 $(1,2,3, \cdots, 761), \mathrm{YS}_{\mathrm{ik}}$ 는 $\mathrm{i}$ 번째 형질의 $\mathrm{k}$ 번째 출생년도 -출생계절 $\mathrm{i}=(1,2,3, \cdots, 48), \mathrm{b}_{\mathrm{i}}$ 는 측정일령의 1 차식 회귀계수, $\mathrm{X}_{\mathrm{ijkl}}$ 는 $\mathrm{i}$ 번째 형질의 1 번째 측정일령의 공변이 (Covariate), $\mathrm{PE}_{\mathrm{ijkl}}$ 는 영 구환경 임의효과 $\sim \mathrm{N}(0, \mathrm{P}), \mathrm{a}_{\mathrm{ijk} k}$ 는 개체의 상가적 유전효과 $\sim \mathrm{N}(0, \mathrm{G}), \mathrm{e}_{\mathrm{ijk} k}$ 는 각 측정치의 임의오차 $\sim \mathrm{N}(0, \mathrm{R})$ 이며, 상기 설정한 혼합모형 설정을 위한 환경효과 분석에는 $\mathrm{PC}$ 용 $\mathrm{SAS}$ package ver 9.1.3을 이용하였고, 혈통 자료의 Renumbering과 Fixed effect와

\section{measurement, age of measurement and location of measurement}


Random effect의 재 정렬을 위하여 RENUMF90(2001, Misztal) 을 사용하였으며, 유전모수 추정을 위하여 EM-REML algorithm 을 바탕으로 Fortran 기반에서 개발된 REMLF90 (Misztal, 2001) 을 이용하여 잔차분산이 $10^{-11}$ 이하로 수렴 될 때까지 반복 추정 하여 Variance-covariance 값을 구하였다.

\section{결과 및 고찰}

1. 자료의 기초통계

Table 2에는 총 36,893 두의 한우 암소 초음파 측정치에 대한

Table 2. Descriptive statistics for ultrasound measurement traits of Hanwoo cows

\begin{tabular}{|c|c|c|c|c|c|c|c|}
\hline Item & No. & Mean & Std & Min & Max & $\mathrm{CV}$ & SKEW \\
\hline \multicolumn{8}{|c|}{1 time record } \\
\hline GIR & 23,792 & 178.9 & 8.89 & 140 & 230 & 4.97 & 0.36 \\
\hline BCS & 23,792 & 4.85 & 1.31 & 1 & 9 & 26.99 & 0.41 \\
\hline UEMA & 23,792 & 57.24 & 11.25 & 26 & 91 & 19.66 & 0.06 \\
\hline UBF & 23,792 & 4.30 & 2.98 & 1 & 15 & 69.21 & 1.07 \\
\hline UMS & 23,792 & 1.94 & 1.13 & 1 & 9 & 57.94 & 1.44 \\
\hline \multicolumn{8}{|c|}{2 time record } \\
\hline GIR & 9,834 & 179.26 & 8.38 & 148 & 228 & 4.67 & 0.23 \\
\hline BCS & 9,834 & 4.87 & 1.23 & 1 & 9 & 25.33 & 0.36 \\
\hline UEMA & 9,834 & 57.58 & 10.16 & 27 & 90 & 17.64 & 0.18 \\
\hline UBF & 9,834 & 4.58 & 2.91 & 1 & 15 & 63.64 & 0.95 \\
\hline UMS & 9,834 & 1.74 & 1.03 & 1 & 8 & 59.1 & 1.75 \\
\hline \multicolumn{8}{|c|}{3 time record } \\
\hline GIR & 2,550 & 179.81 & 8.68 & 154 & 216 & 4.83 & 0.31 \\
\hline BCS & 2,550 & 4.76 & 1.20 & 1 & 9 & 25.14 & 0.17 \\
\hline UEMA & 2,550 & 57.69 & 9.86 & 30 & 91 & 17.08 & 0.19 \\
\hline UBF & 2,550 & 4.44 & 2.76 & 1 & 15 & 62.23 & 0.97 \\
\hline UMS & 2,550 & 1.64 & 0.96 & 1 & 7 & 58.88 & 1.93 \\
\hline \multicolumn{8}{|c|}{4 time record } \\
\hline GIR & 672 & 180.97 & 8.27 & 160 & 210 & 4.57 & 0.47 \\
\hline BCS & 672 & 4.87 & 1.22 & 2 & 9 & 25.16 & 0.11 \\
\hline UEMA & 672 & 58.62 & 9.38 & 28 & 87 & 16.01 & 0.14 \\
\hline UBF & 672 & 4.89 & 2.81 & 1 & 14 & 57.43 & 0.7 \\
\hline UMS & 672 & 1.62 & 0.96 & 1 & 8 & 59.08 & 2.22 \\
\hline \multicolumn{8}{|c|}{5 time record } \\
\hline GIR & 45 & 185.51 & 10.77 & 165 & 213 & 5.81 & 0.21 \\
\hline BCS & 45 & 5.49 & 1.42 & 3 & 9 & 25.95 & 0.49 \\
\hline UEMA & 45 & 62.84 & 14.15 & 25 & 81 & 22.52 & -0.84 \\
\hline UBF & 45 & 7.22 & 3.95 & 1 & 15 & 54.66 & 0.25 \\
\hline UMS & 45 & 2.56 & 1.80 & 1 & 7 & 70.57 & 1.02 \\
\hline \multicolumn{8}{|l|}{ Total } \\
\hline GIR & 36,893 & 179.10 & 8.74 & 140 & 230 & 4.88 & 0.32 \\
\hline BCS & 36,893 & 4.85 & 1.28 & 1 & 9 & 26.41 & 0.38 \\
\hline UEMA & 36,893 & 57.39 & 10.85 & 25 & 91 & 18.91 & 0.08 \\
\hline UBF & 36,893 & 4.40 & 2.95 & 1 & 15 & 67.03 & 1.02 \\
\hline UMS & 36,893 & 1.86 & 1.09 & 1 & 9 & 58.75 & 1.55 \\
\hline
\end{tabular}

$\mathrm{CV}$ : Coefficient of variation, SKEW : Skewness; measurement of the asymmetry of the probability distribution of a real-valued random variable, GIR: Girth, BCS : Body condition score, UMT : Ultrasound measurement traits, UEMA : Ultrasound eye muscle area, UBF : Ultrasound backfat thickness, UMS : Ultrasound marbling score. 
평균과 표준편차를 1 차에서 5 차의 반복측정 차수별로 나타내었다. 배최장근단면적의 평균 및 표준편차는 $57.39 \pm 10.85 \mathrm{~cm}^{2}$ 등지방두 께의 평균 및 표준편차는 $4.4 \pm 2.9 \mathrm{~mm}$, 근내지방도의 평균 및 표 준편차는 $1.86 \pm 1.09$ 로 나타났다. 흥위의 평균은 $179.10 \mathrm{~cm}$ 였고 개체의 비만도로 측정되는 9 단계의 신체충실지수 $(\mathrm{BCS})$ 는 평균 4.85로 조사자의 주관에 따른 차이가 있다 하더라도 평균 5.0정도 로 번식우의 적정 기준치에 적합하다고 사료되었다. Table 3에서 보는 바와 같이 배최장근단면적과 등지방두께 그리고 근내지방도는 다른 형질과는 다르게 초음파 측정시 편차가 크게 나타날 수 있는 형질이기 때문에 평균과 표준편차의 비인 변동계수 $(\mathrm{CV})$ 값이 회차 에 관계없이 다른 형질들에 비하여 상대적으로 크게 나타났다. 또 한 조사된 개체들 중 약 $29.75 \%$ 가 27 단계의 근내지방도 점수에서 최하위의 1 점을 보였는데 이는 측정자의 오차 및 조사된 개체들의 근내지방도 변이성이 정규성에 다소 벗어난 분포를 보이고 있음을 알 수 있었다.

\section{2. 초음파 측정형질의 유전력}

반복모형과 다형질개체모형에 의해 추정된 초음파 측정형질의 유 전력은 Table 3에 제시하였다. 반복모형으로 추정된 배최장근단면 적, 등지방두께, 근내지방도의 유전력은 각각 $0.31,0.38,0.27$ 로 나타났고, 반복력추정값은 배최장근단면적, 등지방두께, 근내지방도
가 각각 $0.46,0.57,0.39$ 로 추정되었다. 유전분산은 각각 18.75 , $1.83,0.17$ 이었으며, 잔차분산은 $32.72,2.04,0.38$, 영구환경분산 은 $9.23,0.91,0.07$ 로 추정되었다. 다형질개체모형으로 추정된 배 최장근단면적, 등지방두께, 근내지방도의 유전분산은 각각 0.78 , $0.35,0.04$ 로 추정되었으며, 환경분산은 $50.52,3.46,0.57$ 로 추정 되었다. 유전력은 각각 $0.02,0.09,0.07$ 로 낮게 추정되었다. 동기 군의 경우 반복개체모형에 맞게 추정하였기 때문에 기본애니멀 모 형에 대한 값이 작게 나온 것으로 사료되어진다. 그러나 유전력이 낮은 형질에 있어서는 개체간의 차이가 주로 환경적인 원인에 의하 여 나타나므로 개체의 표현형에만 근거하여 판단하기 어렵다. 이에 환경효과와 영구환경효과를 고려한 어느 한 형질의 반복기록들에 대해 반복력을 추정하게 된다면 가축 경제형질에 대하여 혹은 종축 으로 더 이용할 것인가 하는 문제를 결정하는데 유익하게 쓸 수 있 을 것으로 사료되어진다.

\section{3. 초음파 측정형질의 유전상관 및 영구환경 상관}

Table 4는 초음파 측정형질에 대한 반복개체모형과 다형질개체 모형을 이용하여 유전상관과 영구환경상관을 나타낸 표이다. 반복 개체모형에서의 배최장근단면적과 등지방두께, 배최장근단면적과 근내지방도, 등지방두께와 근내지방도의 유전상관은 각각 0.69 , 0.54 및 0.59 로 나타났고, 다형질개체모형에서는 각각 0.07 ,

Table 3. Genetic variance $\left(\sigma_{\mathrm{a}}^{2}\right)$, permanent environmental variance $\left(\sigma_{\mathrm{p}}^{2}\right)$, residual variance $\left(\sigma_{\mathrm{e}}^{2}\right)$, repeatability $(r)$ and heritability $\left(h^{2}\right)$ of traits estimated for the data from RRAM and MTAM

\begin{tabular}{lcrrrr}
\hline Item & $\sigma_{\mathrm{p}}^{2}$ & $\sigma_{\mathrm{a}}^{2}$ & $\sigma_{\mathrm{e}}^{2}$ & $\mathrm{~h}^{2}$ & $\mathrm{r}$ \\
\hline \hline RRAM ${ }^{1)}$ & & & & & \\
\hline UEMA & 9.23 & 18.75 & 32.72 & 0.31 & 0.46 \\
UBF & 0.91 & 1.83 & 2.04 & 0.38 & 0.57 \\
UMS & 0.07 & 0.17 & 0.38 & 0.27 & 0.39 \\
\hline MTAM ${ }^{2)}$ & & & & 0.02 & - \\
UEMA & - & 0.78 & 50.52 & 0.09 & - \\
UBF & - & 0.35 & 3.46 & 0.07 & - \\
UMS & - & 0.04 & 0.57 & & \\
\hline
\end{tabular}

${ }^{1)}$ RRAM : Repeated records animal model, ${ }^{2)}$ MTAM : Multiple trait animal model, UEMA : Ultrasound eye muscle area, UBF : Ultrasound backfat thickness, UMS : Ultrasound marbling score.

Table 4. Genetic and permanent environment correlation coefficient among ultrasound measurement traits in Hanwoo cows by RRAM and MTAM

\begin{tabular}{|c|c|c|c|c|c|c|}
\hline \multirow{2}{*}{ Item } & \multicolumn{3}{|c|}{ RRAM $^{1)}$} & \multicolumn{3}{|c|}{ MTAM $^{2)}$} \\
\hline & UEMA & UBF & UMS & UEMA & UBF & UMS \\
\hline UEMA & & 0.69 & 0.54 & & 0.07 & -0.66 \\
\hline UBF & 0.49 & & 0.59 & - & & 0.39 \\
\hline UMS & 0.62 & 0.44 & & - & - & \\
\hline
\end{tabular}

${ }^{1)}$ RRAM : Repeated records animal model, ${ }^{2)}$ MTAM : Multiple trait animal model, UEMA : Ultrasound eye muscle area, UBF : Ultrasound backfat thickness, UMS : Ultrasound marbling score, Upper diagonal matrices are genetic correlation coefficient, Below diagonal matrices are permanent environment correlation coefficient.

$$
-74-
$$


-0.66 및 0.39 로 추정되었다. 반복모형에서는 각 형질간에 정의 상관을 나타내었고, 다형질개체모형에서는 배최장근단면적과 근내 지방도간에 부의 상관을 나타내었다. Kemp 등 (2002)은 초음파 측 정형질인 배최장근단면적과 등지방두께, 배최장근단면적과 근내지 방도, 등지방두께와 근내지방도간의 유전상관이 각각 $0.22,-0.18$ 및 -0.004 로 보고한 결과와 비교하여 반복모형은 높은 상관을 나 타내었다. Noh 등 (2004)은 12개월령 한우의 초음파 측정한 배최 장근단면적과 도축 후 배최장근단면적, 초음파 측정 등지방두께와 도체의 등지방두께, 초음파측정 \%지방함량과 근내지방도에서 유전 상관이 각각 $0.616,0.544,0.501$ 로 비교적 높은 정의 유전상관으 로 나타났다고 보고하였고, 배최장근단면적과 등지방두께, 근내지방 도 간의 유전상관은 각각 $-0.283,0.194$ 로 추정되어 본 연구와는 차이를 보였다. 반복개체모형에 사용된 영구환경상관은 배최장근단 면적과 등지방두께, 배최장근단면적과 근내지방도, 등지방두께와 근 내지방도가 각각 $0.49,0.62$ 및 0.44 로 나타났다.

\section{요 약}

본 연구는 한우 암소 초음파 측정자료 특징을 알아보고, 측정형 질에 대한 유전모수를 추정하여 육질 또는 육량 개량을 위한 기초 자료를 제공하기 위해 수행되었으며, 2001년부터 2009년까지 한국 종축개량협회에 의해 측정된 한우 암소 36,893 두를 이용하였고, 그 중 반복기록이 있는 개체는 7,913두였다.

유전모수 추정을 위하여 반복개체모형을 이용하였으며, 유전모수 추정에는 REMLF90 (Miztal, 2001)을 이용하였다. 유전모수 추정 모형의 설정을 위하여 흥위, 영양도 및 초음파 측정치에 대한 출생 년도, 출생계절, 측정년도, 측정계절, 측정지역, 측정연령 등의 환경 효과를 추정하였다.

반복개체모형으로 추정된 배최장근단면적, 등지방두께 및 근내지 방도에 대한 유전력이 각각 $0.31,0.38,0.27$ 로 나타났고, 다형질개 체모형으로 추정한 유전력은 각각 $0.02,0.09,0.07$ 로 낮게 추정되 었다.

반복개체모형을 이용한 반복력은 배최장근단면적, 등지방두께, 근 내지방도가 각각 $0.46,0.57,0.39$ 로 나타났다. 분석모형 간의 추정 치의 차이를 비교 할 때 반복모형에서의 유전력과 반복력이 높게 추정되었다.

따라서 반복형질 값을 가진 형질들의 측정치를 표준화하여 한우 암소개량을 위한 기초자료로 활용된다면 유전능력평가와 개량사업 비용절감에 도움이 될 것으로 기대된다.

(주제어: 반복개체모형, 초음파 측정형질, 한우암소)

$$
\text { 사 사 }
$$

본 연구에 도움을 주신 한국종축개량협회에 감사드리며 참여한 대학원생은 교육과학기술부 2 단계 $\mathrm{BK} 21$ 사업의 소속 대학원생으로
서 사업단의 지원에 감사드립니다.

\section{인 용 문 헌}

Brethour, J. R. 1992. The repeatability and accuracy of ultrasound in measuring backfat of cattle. J. Anim. Sci. 1992. 70:1039-1044.

Hamlin, K. E., Green, R. D., Cundiff, L. V., Wheeler, T. L. and Dikeman, M. E. 1995a. Real-time ultrasonic measurement of fat thickness and longissimus muscle area : $\Pi$. Relationship between real-time ultrasound measurementss and carcass retail yield. J. Anim. Sci. 73:1725-1734.

Kemp, D. J., Herring, W. O. and Kaiser, C. J. 2002. Genetic and environmental parameters for steer ultrasound and carcass traits. J. Anim. Sci. 80:1489-1496.

Kim, H. C., Jeon, G. J., Na, K. J., Yoo, Y. M. and Chung, J. K. 1995. Breeding and Genetics ; A Study on estimation of carcass traits in live Hanwoo by using the ultrasonic scanning method. J. Anim. Sci. Vol. 37, No, 4. 336-340.

Koo, Y. M. 2007. Estimation of genetic correlation and parameters for ltrasound measurements and perfomance test data in Hanwoo cows. Gyeongsang National University a mastral dissertation.

Lee, D. H. 2004. Breeding and Genetics:Methods for genetic parameter estimations of carcass weight, longissimus muscle area and marbling score in korean cattle. J. Anim. Sci. Vol.46, No.4. 509-516.

Misztal, I. 2001. RENUMF90 - renumbering program for the BLUPF90. Online. Available : http://nce.ads.uga.edu/ ignacy/numpub/ blupf $90 /$ docs/Readme.renumf 90

Misztal, I. 2008. BLUPF90 - a flexible mixed model program in Fortran 90. Online. Available :http://nce.ads.uga.edu/ ignacy/ numpub/blupf90/docs/blupf90.pdf.

Roh, S. H., Kim, C. Y., Won, S. Y., Park, C. J., Lee, S. S., Lee, J. G.. 2010. Breeding and Genetics : Studies on genetic parameter estimation and sire selection to ultrasound measurement traits of Hanwoo. J. Anim. Sci. 2010. Vol.52, No.1. 1-8.

Schaeffer, L. R. 2001. Animal Models -ANSC* 6370-Winter 2001.

Stelzleni, A. M., Perkins, T. L., Brown, A. H. Jr., Pohlman, F. W., Johnson, Z. B. and Sandelin, B. A. 2002. Genetic parameter estimates of yearling live animal ultrasonic measurements in Brangus cattle. J. Anim. Sci 80:3150-3153.

Van vleck, L. D. 1987. Contemporary grous for genetic evaluations. Faculty papers and publications in animal science.

Waldner, D. N., Dikeman, M. E., Schalles, R. R., Olson, W. G., Houghton, P. L., Unruh, J. A. and Corah, L. R. 1992. Validation of real-time ultrasound technology for predicting fat thicknesses, longissimus muscle areas, and composition of Brangus bulls from 4 months to 2 years of age. J. Anim. Sci. 1992 70:3044-3054.

(Received Nov. 10, 2011; Revised Feb. 21, 2012; Accepted Mar. 28, 2012) 